\title{
ARTICLE
}

\section{Estimation of surface concentration of radon decay products from gamma dose rate change after rain}

\author{
Jun Hirouchi $^{a^{*}}$, Shigekazu Hirao ${ }^{\text {a }}$, Jun Moriizumi ${ }^{\mathrm{a}}$, Hiromi Yamazawa ${ }^{\mathrm{a}}$ and Atsuo Suzuki ${ }^{\mathrm{b}}$ \\ ${ }^{a}$ Nagoya University, Furo-cho, Chikusa-ku, Nagoya, Aichi-ken, 464-8603, Japan; ${ }^{b}$ Shizuoka Prefectural Environmental Radiation \\ Monitoring Center, 5814-19, Ikeshinden, Omaezaki, Shizuoka-ken, 437-1612, Japan
}

\begin{abstract}
A method to estimate the surface concentration of radon decay products ${ }^{214} \mathrm{~Pb}$ and ${ }^{214} \mathrm{Bi}$ from gamma dose rate changes due to rainfall has been developed. The conversion from the dose rate to surface concentration was performed by a dose rate model considering geometric conditions such as buildings and ground undulations around each monitoring station (MS). This method of calculating dose rate increase (DRI) was successful in reproducing the difference in the shape of the DRI decrease due to differences in the initial ${ }^{214} \mathrm{Bi} /{ }^{214} \mathrm{~Pb}$. The estimated concentration exhibited differences among the MSs despite uniform depositions. This difference was considered to have been caused by surface run-off and infiltration of radionuclides.
\end{abstract}

Keywords: gamma dose rate; surface concentration; radon decay products; rain

\section{Introduction}

Environmental gamma dose rates are continuously monitored around nuclear power plants by environmental radiation monitoring systems to identify the release of radionuclides from these plants. It is important to ensure that dose rates remain confined to natural variability. During an accident, dose rates and radioactivity concentrations on the ground surface and in the air are measured at many points to evaluate the radiological doses inflicted on the public in addition to soil contamination. However, the measurement process of radioactivity concentration is time-consuming, because, in most cases, samples collected in the field are to be delivered to the laboratory for measurement. On the other hand, dose rate measurements have the advantage of being conducted in-situ to provide real-time data continuously as part of responsible emergency countermeasures. To take complete advantage of dose rate measurements, the capability of estimating radioactivity concentrations in environmental media from the dose rate is useful.

Most estimations of surface radioactivity concentrations from dose rate measurements were commonly made under the assumption that the deposited radionuclides exhibit uniform distribution on the infinite ground surface and that the height of the effective center of the radiation detector is $1 \mathrm{~m}$ above ground [1-3]. However, this assumption is rarely valid because obstacles such as buildings are present around

*Corresponding author. Email: hirouchi.jun@ @.mbox.nagoyau.ac.jp monitoring points. In addition, the height of the radiation detector is not always $1 \mathrm{~m}$. Therefore, the inadequacy of the assumptions may result in differences between estimated values of surface radioactivity concentration in previous studies and actual values. Therefore, the estimation of radioactivity concentration from dose rate measurements should consider the shielding effects and the source distribution due to buildings and ground surface undulations around each measuring point, hereafter referred to as geometric conditions.

Increases in dose rates in a normal situation during rain events are attributed to the deposition of radon decay products, ${ }^{214} \mathrm{~Pb}$ and ${ }^{214} \mathrm{Bi}$, in rain water $[4,5]$. The gamma rays emitted from the radon decay products attenuate and scatter in air and materials. And then they contribute to the dose rate. The gamma rays emitted from the radionuclides released in an accident occur through a similar transfer process. Once evaluated from dose rate changes in a normal situation, it is expected that these shielding effects due to geometric conditions can be applied in an accidental situation to more realistically estimate surface concentrations. Therefore, the purpose of this study is to develop an estimation method of the surface concentrations of radon decay products from dose rate increments due to rain that considers geometric conditions around MSs.

\section{Estimation method}

The present method has two main features: precise representation of the geometric conditions of sources and the shielding effect in the dose rate model, and 
reasonable estimation of the ${ }^{214} \mathrm{Bi} /{ }^{214} \mathrm{~Pb}$ ratio from the tendency of dose rate change after rain.

\subsection{Dose rate model}

The gamma dose rate from the radon decay products on the ground surface is calculated by integrating contributions from each segment $d s\left(\mathrm{~m}^{2}\right)$ of the ground surface as

$$
\begin{aligned}
& d D=\sum_{i=P b, B i} \sum_{j} C_{i, j} \cdot d s \cdot \frac{K}{4 \pi r^{2}} \cdot E_{i} \cdot \mu_{\text {air }}\left(E_{i}\right) \cdot S \\
& S=\prod_{m}^{N}\left(\exp \left(-\mu_{m}\left(E_{i}\right) \cdot r_{m}\right) \cdot B_{m}\right)
\end{aligned}
$$

where the outer summation is for the radon decay products ${ }^{214} \mathrm{~Pb}$ and ${ }^{214} \mathrm{Bi}$, and the inner summation accounts for the gamma ray from the radionuclide deposited on the each segment $j$. The term $d D$ is the dose rate $\left(\mathrm{nGy} \mathrm{h} \mathrm{h}^{-1}\right), C$ is the surface concentration $\left(\mathrm{Bq} \mathrm{m}^{-2}\right)$, $E$ is the gamma-ray energy $(\mathrm{eV}), K$ is the conversion factor of the unit of energy from $\mathrm{eV}$ for $E$ to $\mathrm{nGy} \mathrm{h}^{-1}$ for $d D, r_{j}$ is the distance of a segment $j$ of the gamma ray path, $\mu$ is the linear attenuation coefficient $\left(\mathrm{m}^{-1}\right), S$ is the term considering the shielding and the build-up effects of air and materials, and $B$ is the build-up factor. The subscript $m$ indicates air or materials such as soil or concrete. This model considers the geometric conditions around each MS and the height of the $\mathrm{NaI}(\mathrm{Tl})$ scintillation detector on the basis of field investigations.

\subsection{Estimation of ${ }^{214} \mathrm{Bi}^{214} \mathrm{~Pb}$ ratio}

In this study, the DRI due to rain is defined as the dose rate increment from the reference background level contributed by the radionuclide permanently occurring in soil. We estimated ${ }^{214} \mathrm{Bi} /{ }^{214} \mathrm{~Pb}$ from the DRI measured after rain stopped because the temporal change in the DRI is considered to be caused solely by decay of the two nuclides. These radon decay products were assumed to remain on the ground surface without being affected by surface runoff, inflow, or infiltration. It was reported that the ${ }^{218}$ Po concentration in raindrops deposited on the ground surface was a few orders of magnitude less than ${ }^{214} \mathrm{~Pb}$ and ${ }^{214} \mathrm{Bi}$ concentrations [5]. Hence, ${ }^{218} \mathrm{Po}$ was assumed not to contribute to the temporal change in surface concentration of the radon decay products. The temporal changes in the surface concentration are governed by the following equations:

$$
\begin{aligned}
& \frac{d C_{P b}}{d t}=-\lambda_{P b} C_{P b} \\
& \frac{d C_{B i}}{d t}=-\lambda_{B i} C_{B i}+\lambda_{B i} C_{P b}
\end{aligned}
$$

where $\lambda$ is the decay constant $\left(\mathrm{s}^{-1}\right)$.

The conversion factors from the surface concentrations to DRI were calculated by the dose rate model. In this study, the radon decay products are assumed to distribute uniformly on horizontal surfaces that catch raindrops. The calculation domain is a $60 \mathrm{~m}$ square and is divided into $0.1 \mathrm{~m}$ square segments. DRI can be expressed by the surface concentrations and the conversion factors $\Gamma\left(\left(\mathrm{nGy} \mathrm{h}^{-1}\right)\left(\mathrm{Bq} \mathrm{m}^{-2}\right)^{-1}\right)$,

$$
d D_{c a l}=C_{P b} \Gamma_{P b}+C_{B i} \Gamma_{B i}
$$

The examples of DRI calculated with Eqs. (3)-(5) are shown in Figure 1. The initial DRI was set to be $1 \mathrm{nGy}$ $\mathrm{h}^{-1}$. It can be seen from Figure 1 that the temporal changes in DRI differ depending on the initial surface concentration ratio of ${ }^{214} \mathrm{Bi}$ to ${ }^{214} \mathrm{~Pb}$. When the initial ${ }^{214} \mathrm{Bi} /{ }^{214} \mathrm{~Pb}$ is 1.5 , DRI decreases in an exponential fashion associated with temporal changes in the ${ }^{214} \mathrm{Bi}$ surface concentration. When the initial ${ }^{214} \mathrm{Bi} /{ }^{214} \mathrm{~Pb}$ is 0.7 , DRI increases gradually in approximately the first 10 min, and decreases in an exponential fashion. This increase is due to productions of ${ }^{214} \mathrm{Bi}$, which contribute more to the dose rate than ${ }^{214} \mathrm{~Pb}$. The differences in the temporal change in DRI due to the initial ${ }^{214} \mathrm{Bi} /{ }^{214} \mathrm{~Pb}$ were detected in the measured data analyzed in this study.

In this study, the surface concentrations of ${ }^{214} \mathrm{~Pb}$ and ${ }^{214} \mathrm{Bi}$ at the time when rain stopped were determined by using a least-square method in which the square sum of differences in DRI between observations and calculations

$$
\Delta=\sum\left(d D_{o b s}-d D_{c a l}\right)^{2}
$$

is minimized.

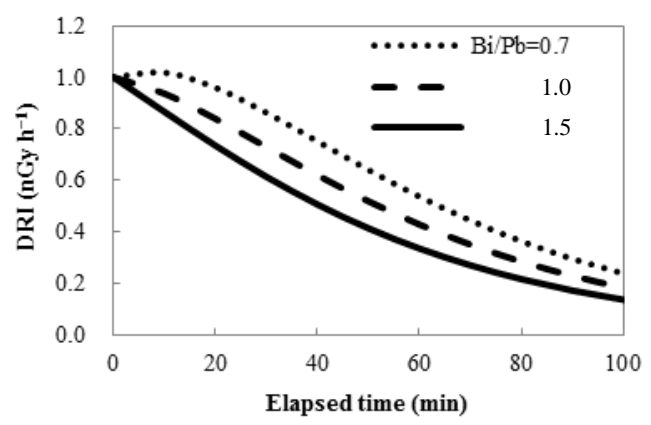

Figure 1. Initial ${ }^{214} \mathrm{Bi} /{ }^{214} \mathrm{~Pb}$ ratio dependence of dose rate increase (DRI).

\subsection{Analysis condition}

Rain events were selected in which both of the following two criteria regarding DRI were met: DRI at the time when rain stopped is larger than $5 \mathrm{nGy} \mathrm{h} \mathrm{h}^{-1}$ and $\Delta$ normalized by the analysis time is less than 0.01 (nGy $\left.\mathrm{h}^{-1}\right)^{2} \mathrm{~min}^{-1}$. The dose rate usually fluctuates slightly by factors other than the chain decay of ${ }^{214} \mathrm{~Pb}$ and ${ }^{214} \mathrm{Bi}$. The main causes are variations in the radon concentration in air [6] and migration of the radionuclides due to surface run-off or infiltration. The above-mentioned criteria were set to reduce the influence of error from these factors.

Moreover, two additional rain criteria were set to select rain events for analysis: the difference in rain intensity among the MSs is less than $0.5 \mathrm{~mm}$ during each $10 \mathrm{~min}$ period, and the difference in accumulated amount of rainfall is less than $10 \mathrm{~mm}$. It was reported that radon progeny concentrations in raindrops differ depending on rain intensity $[4,5]$. The purpose of setting these additional criteria is to select rain events in which ${ }^{214} \mathrm{~Pb}$ and ${ }^{214} \mathrm{Bi}$ depositions are considered to be uniform 
in the area where objective MSs are located.

\subsection{Environmental data}

This estimation method for surface concentration was applied to routine observations of the dose rate during the period 2004-2010 with $3 " \phi \times 3$ " NaI(Tl) scintillation detectors at near-by seven MSs around the Hamaoka nuclear power plant in Shizuoka, Japan. Measurement data were acquired every $10 \mathrm{~min}$.

\section{Results and discussion}

\subsection{Calculation result of dose rate model}

Before applying the dose rate model to DRI analyses, the model was checked by comparing the calculated dose rates for no-rain conditions with respective observation results. The calculation performed by inputting the geometric conditions for each MS and the radioactivity concentrations in soil and MS roof obtained by in-situ HPGe measurements. The results are shown in Figure 2. The model is successful in representing the dose rate at each MS within 15\%. It seems that the calculated value is lower in lower value (below $40 \mathrm{nGy} \mathrm{h}^{-1}$ ) and higher in higher region (above $45 \mathrm{nGy} \mathrm{h}^{-1}$ ). The air concentration of radon was not input in the dose rate model. Therefore, the calculations are lower than the actual values. In addition, we were not able to measure the radioactivity concentration in building walls. Hence, the radioactivity concentration in MS roof was input as substitute for that in building walls. The radioactivity concentration in building wall may be smaller than that in MS roof, though we were not able to

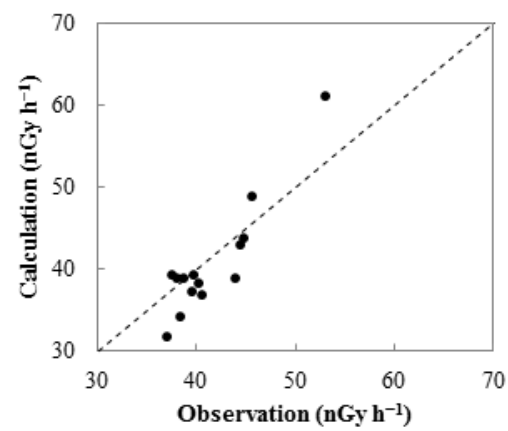

Figure 2. Comparison of the calculated dose rate with observations in no-rain condition. check it. In higher region, there are many buildings around MS. Therefore, the calculation value may be higher in higher region.

The conversion factors calculated with the dose rate model and the mean DRI observations for each MS are summarized in Table 1. The conversion factors differ due to differences in the geometric conditions of each MS. The calculated conversion factor is small at MSs at which the observed mean DRI is small. It can be seen from Table 1 that the contribution of radon decay products on the roof is comparable to those occurring on ground surfaces and is much larger at MSs with large ground surface areas. It is discovered that the ratios of $\Gamma_{B i}$ to $\Gamma_{P b}$ differ among MSs. The energy of the gamma ray emitted from ${ }^{214} \mathrm{~Pb}$ is lower than from ${ }^{214} \mathrm{Bi}$, which causes larger attenuation of the gamma ray of ${ }^{214} \mathrm{~Pb}$ than that of ${ }^{214} \mathrm{Bi}$. This result indicates that $\Gamma_{B i} / \Gamma_{P b}$ depends on the amount of obstacles around MS. According to field investigations, more obstacles such as buildings are present around Nakamachi than those around other MSs. Therefore, the conversion factor for Nakamachi was calculated by the dose rate model to be the smallest and the $\Gamma_{B i} / \Gamma_{P b}$ was the largest.

\subsection{Estimation of surface concentration}

The examples of the temporal change in DRI after the rain stopped are shown in Figure 3. In the rain events shown in Figure 3(a), DRI first decreased gradually before showing a steeper decrease from 10 to $20 \mathrm{~min}$ after the rain stopped. While in Figure 3(b), DRI decreased without showing the gentle-decrease phase illustrated in Figure 3(a). These features were common for all MSs. The present method of calculating DRI is successful in reproducing these features. The difference in shape of the DRI decrease is reasonably attributed to the differences in the ${ }^{214} \mathrm{Bi} /{ }^{214} \mathrm{~Pb}$ ratio, with smaller value as the case in Figure 3(a). It can also be pointed out that the difference of 0.1 in the ${ }^{214} \mathrm{Bi} /{ }^{214} \mathrm{~Pb}$ ratio causes small but discernible differences in the DRI curves.

The relationship between the initial surface concentrations of ${ }^{214} \mathrm{~Pb}$ and ${ }^{214} \mathrm{Bi}$ averaged for rain events and the fractional contribution of DRI from the radon decay products on the MS roof and paved area for each MS is shown in Figure 4. Here, the area on which the radon decay products deposited was assumed to

Table 1. Conversion factors from surface concentration to dose rate increase (DRI) and mean DRI observations for each monitoring station (MS).

\begin{tabular}{|c|c|c|c|c|c|c|c|c|c|}
\hline \multirow{2}{*}{ MS } & \multirow{2}{*}{$\begin{array}{c}\text { MS roof } \\
\text { size* }\end{array}$} & \multicolumn{3}{|c|}{$\Gamma_{P b}\left(\mathrm{nGy} \mathrm{h}^{-1}\right) /\left(\mathrm{kBq} \mathrm{m}^{-2}\right)$} & \multicolumn{3}{|c|}{$\Gamma_{B i}\left(\mathrm{nGy} \mathrm{h}^{-1}\right) /\left(\mathrm{kBq} \mathrm{m}^{-2}\right)$} & \multirow{2}{*}{$\begin{array}{l}\Gamma_{P b} / \Gamma_{B i} \\
\text { for ground }\end{array}$} & \multirow{2}{*}{$\begin{array}{l}\text { mean DRI } \\
\left(\mathrm{nGy} \mathrm{h}^{-1}\right)\end{array}$} \\
\hline & & MS roof & Ground & Total & MS roof & Ground & Total & & \\
\hline Nakamachi & $\mathrm{L}$ & 0.199 & 0.091 & 0.289 & 1.18 & 0.66 & 1.83 & 7.24 & 9.2 \\
\hline Center & M & 0.193 & 0.125 & 0.318 & 1.14 & 0.88 & 2.02 & 7.01 & 11.2 \\
\hline Kusabue & XL & 0.227 & 0.104 & 0.331 & 1.34 & 0.71 & 2.05 & 6.82 & 11.3 \\
\hline Sakuragaike & $S$ & 0.154 & 0.179 & 0.333 & 0.91 & 1.25 & 2.16 & 6.96 & 11.8 \\
\hline Hiraba & S & 0.162 & 0.185 & 0.346 & 0.96 & 1.25 & 2.21 & 6.79 & 12.7 \\
\hline Shirasuna & S & 0.166 & 0.186 & 0.353 & 0.98 & 1.26 & 2.24 & 6.75 & 12.8 \\
\hline Shinkango & XL & 0.222 & 0.156 & 0.378 & 1.32 & 0.94 & 2.26 & 6.04 & 12.6 \\
\hline
\end{tabular}

*MS roof size $(\mathrm{m})$ : XL $(6.8 \times 4.8), \mathrm{L}(5.0 \times 4.5), \mathrm{M}(4.7 \times 3.6), \mathrm{S}(4.0 \times 3.0)$. 

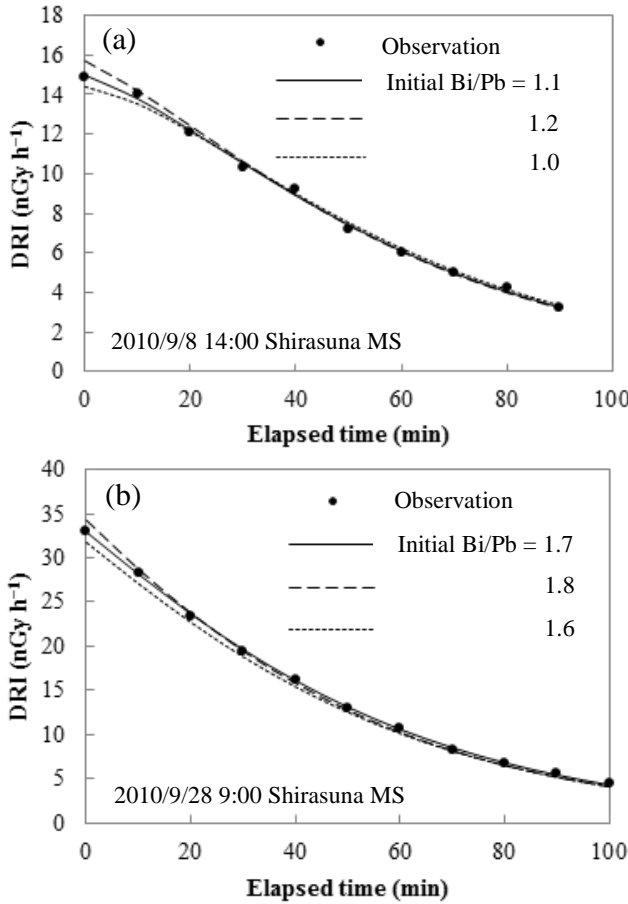

Figure 3. Examples of the temporal change in dose rate increase (DRI) after rain stopped.

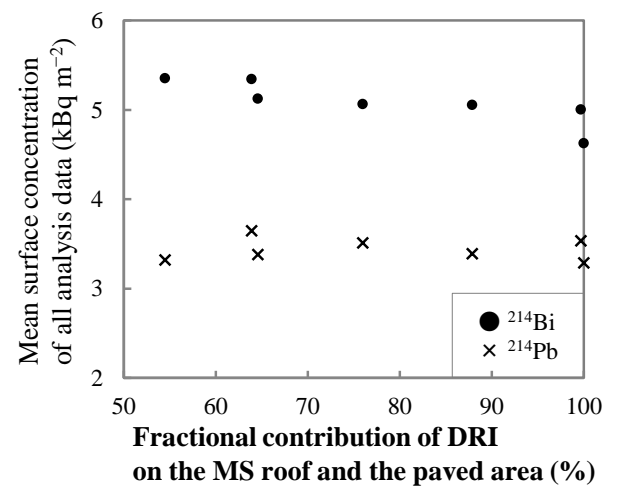

Figure 4. Relationship between the mean surface concentration and the fractional contribution of dose rate increase (DRI) for each monitoring station (MS).

include MS roofs, paved areas, and soil areas. The rain events subjected to analysis were selected by criteria in which ${ }^{214} \mathrm{~Pb}$ and ${ }^{214} \mathrm{Bi}$ depositions were considered to be uniform in the MSs area. Nevertheless, it can be seen from Figure 4 that the estimated concentrations of ${ }^{214} \mathrm{Bi}$ differ by approximately $15 \%$ with systematically smaller concentrations estimated for MSs with larger dose rate contributions from the MS roofs and paved areas. In contrast, those of ${ }^{214} \mathrm{~Pb}$ have small differences among the MSs within $8 \%$ and do not exhibit the systematical differences. The MS roofs are coated with rubber and have a gentle slope, which implies higher efficiency in the surface run-off of rain water than that in the soil area. Thus, the amount of radionuclides existing on MS roofs and paved areas is considered to be less than that on the soil areas. Therefore, it is highly probable that the negative correlation detected in ${ }^{214} \mathrm{Bi}$ is caused by the surface run-off.
However, the negative correlation is not detected in ${ }^{214} \mathrm{~Pb}$. In soil areas, the attenuation becomes larger due to the infiltration of the radionuclides. Therefore, the estimated concentration of ${ }^{214} \mathrm{~Pb}$ for the MSs with a larger dose rate contribution from soil areas is thought to become smaller. It is probable that the no correlation detected in ${ }^{214} \mathrm{~Pb}$ is caused by the competition between the surface run-off and the infiltration.

\section{Conclusion}

A method to estimate surface concentration of the radon decay products from DRI due to rain has been proposed. The dose rate was converted into surface concentration with the dose rate model, which was successful in representing the dose rate at each MS within 15\%. The present method of calculating DRI was successful in reproducing the difference in shape of the DRI decrease carves due to the difference in the initial ${ }^{214} \mathrm{Bi} /{ }^{214} \mathrm{~Pb}$ ratio. It was also pointed out that surface run-off process and infiltration process had substantial effects to the estimated concentrations. More precise treatment of these effects in the model would improve the performance of the model.

\section{Acknowledgements}

The authors would like to thank the staff of Shizuoka Prefectural Environmental Radiation Monitoring Center for the provision of dose rate and support for the land survey around the MSs. This work in supported by JSPS KAKENHI Grant Number 24360392.

\section{References}

[1] H. Velasco, M. Rizzotto, N. Merkis, M. Belli and U. Sansone, Contribution to the external gamma dose rate from ${ }^{137} \mathrm{Cs}$ and ${ }^{40} \mathrm{~K}$ activity concentrations determined in the vertical profile of sandy beaches, J. Radioanal. Nucl. Chem. 273, (2007), pp.395-399.

[2] H. L. Beck, J. DeCampo and C. Gogolak, In situ Ge (Li) and $\mathrm{NaI}(\mathrm{Tl})$ gamma-ray spectrometry, HASL-258, U.S. Atomic Energy Commission, New York, NY10014 (1972).

[3] J. R. Lamarsh, Introduction to Nuclear Engineering,

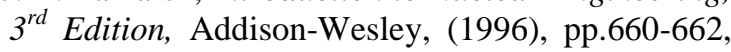
ISBN 0201824981.

[4] N. Fujinami, Observational study of the scavenging of radon daughters by precipitation from the atmosphere, Environ. Int, 22, (1996), pp.181-185.

[5] M. C. Horng and S. H. Jiang, In situ measurements of gamma-ray intensity from radon progeny in rainwater, Radiat. Meas. 38, (2004), pp.23-30.

[6] H. Yoshida, M. Aika, A. Iki, Y. Ibuki and R. Goto, Fluctuation Factors of Ambient Dose Rates in the Vicinity of Hamaoka Nuclear Power Plant, Radioisotopes 53, (2004), pp.405-413. 